\title{
Research on the Construction Path of building Judicial Team in the Intermediate Court
}

\author{
Wu Shixin \\ Criminal Justice College of East China University of Political Science and Law \\ Songjiang, Shanghai, China
}

Keywords: Trial team, Collegiate bench, Build path.

\begin{abstract}
Under the background of the reform of judicial responsibility system and the judiciary stuff quotient system, in order to solve the problems of "The judge does not judge, the referee does not hear" and the serious administrative traces, the establishment of new trial team has become an urgent task that courts of all levels are faced with. In this process, due to the inherent characteristics of the Intermediate Court, it is necessary to take into account factors such as the trial grade, geography, case quality, and human resources. At the same time, the relationship between the newly formed trial team and the original statutory body such as the collegiate bench needs to be further clarified. For the formation of the trial team of the Intermediate People's Court, the $3+\mathrm{N}+\mathrm{N}$ model is worth trying. But firstly, it should be divided according to the scope of case management of different business courts, and then refined according to the actual situation faced by each team and further Arrangements will eventually result in a trial team model with the input judges at the core and the appropriate number of judge assistants and clerks.
\end{abstract}

\section{The trial team produces background interpretation and conceptual framework}

\subsection{Analysis of relevant policies and backgrounds of the trial team}

In November 2013, the central government made a comprehensive plan for intensifying the reform of the judicial system. The "Decision on the Central Committee of the Communist Party of China on Comprehensively Deepening the Reform of Some Major Issues" proposed to improve the responsibility system for trial judges and collegial panels, letting the judge referee and making responsible referee. What's more, It's important to remove the administrative management of the internal management of the court and promote the flat management of the trial organization. At the end of 2013, the Supreme People's Court launched pilot project for the reform of the operational mechanism for jurisdiction throughout the country.

By 2017, classification management of judicial personnel is basically in place, and judges, judicial support personnel, and judicial administrative personnel are all in place and perform their duties. Courts in China have selected 120,138 post judges from the original 21,1990 judges through strict examinations, selection committees, and NPC appointments.[1] At the same time, with the reform of the case registration system, the number of cases has increased, and the reform of the post system has reduced the number of judges nationwide from $58 \%$ to $33 \%$ of the number of editors. Therefore, the contradiction between the increasing court case and reducing judges is more prominent.

The construction of the trial team is the result of judicial reform. The establishment of the trial team is the need for the reform of the judicial responsibility system, and it is also a powerful grasp of the contradiction of case. Various courts across the country initiated the experimental reform, explored the construction of the trial team, and added the assistants of the judges to the traditional "Judges + Clerks" and other traditional case-handling modes and divide the labor to carry out trial work. In order to realize the specialization of the judges, it is necessary to establish an excellent trial team and form a division of personnel and functions that conforms to the rule of adjudication. 


\subsection{Analysis of the conceptual and characteristics of the trial team}

\subsubsection{Judicial team conceptual}

In the second section of the Supreme People's Court's "Several Opinions on Perfecting the Judicial Responsibility System of the People's Court" (hereinafter referred to as "the Judicial Responsibility System"), the section on "The Operation Mechanism of the Independent System and the Collegiate Bench" clearly states: The grassroots and intermediate people's courts may form trial team composed of a judge and judge assistants, clerks and other necessary supporting personnel, and handle cases involve summary procedures and other cases stipulated by law .The Grassroots Court that has relatively more cases can form a relatively fixed trial team and implement a flat management model."

Based on the contents of the "Judicial Responsibility System" and local practice, this paper attempts to define the concept of the trial team. The trial team is a trial power allocation unit composed of judges and trial support personnel (including judge assistants, clerk, etc.) formed by the people's courts in order to improve the quality of trials. It has the characteristics of relatively fixed, close cooperation and self-management.[2]

\subsubsection{Judging the characteristics of the trial team}

Combined with the original intention of the trial team and the practice results of various places, the trial team presents the following characteristics:

First, the trial team is focused on senior post judges. In the trial team, the judge is at heart element and is the dominant player in the team. They are the organizer and commander of all the work and activities of the trial team. The judge mainly exercises the management of the team by witnessing trial, studying case and team management. And the judge directly responsible for all the work of the team.

Second, the trial team isn't a statutory trial organization. According to the existing laws of our country, there are only distinct courts,collegial panels and committees for statutory trial organizations. The trial team is a process organization composed of a number of judges and trial support personnel. It can be used as a trial management unit and a performance evaluation unit, but the mature subject is still the legal trial organization generated from the team. Distinguishing between the trial team and the statutory trial organization helps to the implementation of the judicial responsibility system.

Third, the internal structure design of the trial team should be simplified. The goal of the reform of the operational mechanism of jurisdiction is to realize de-administration and achieve flat management. If there are too many internal levels, it is easy to produce administrative management within the team. Consequently, the internal structure of the trial team should be simplified. Before the reform of judicial responsibility system, the upper-level leaders carried out level-by-level management of the lower-level cadres, and the "judgment attribute" of jurisdiction was replaced by the administrative "subjective attribute", which evolved into "The judge does not judge, the referee does not hear, and responsibilities are not Clear" question. This not only reduces the efficiency of the trial, but also completely violates the rule of jurisdictional operation. If there are multiple levels within the trial team, it will inevitably hinder the advancement of the de-administrative process.

\section{Analysis and reference of the existing experience of the trial team}

\subsection{Based on the whole country: the existing pattern of domestic trial team construction}

Since the test of trial team construction, the various courts across the country have built different kinds of trail team by combining the actual construction models of each court. Different types of trial teams have achieved good results in terms of raising the settlement rate and reducing the number of complaints. The following table selects some of the pilot courts with outstanding results to show the trend of the number of cases settled before and after the trial team construction. 
Table 1: Comparison of the number of cases settled before and after the trial team construction

\begin{tabular}{|c|c|c|c|}
\hline & $\begin{array}{c}\text { Number of cases } \\
\text { settled before the } \\
\text { reform }\end{array}$ & $\begin{array}{c}\text { Number of cases settled } \\
\text { after the reform }\end{array}$ & Growth ratio \\
\hline Jiangyin Court of Jiangsu Province & 14998 & 22962 & $53.1 \%$ \\
\hline Futian Court of Fujian Province & 41548 & 52664 & $26.9 \%$ \\
\hline Lixia Court of Shandong Province & 11999 & 14843 & $23.7 \%$ \\
\hline Shanghai Second Intermediate People's Court & 19374 & 22032 & $13.7 \%$ \\
\hline
\end{tabular}

In cases where criminal probation procedures or civil summary procedures can be applied according to law, a trial team consisting of one judge and several trial assistants is often established, and the judges in the team are solely responsible for trial. The trial team of the unconstrained system effectively improves the efficiency of the judiciary and raises the sense of responsibility of judges. For cases using the collegiate system, they should be divided into relatively fixed collegiate type and random composition collegiate type. Preparation of judge assistants and clerk is different, so it is indicated by n.

\subsubsection{Relatively fixed collegiate type within the team}

Jilin, Guangdong Foshan, Shenzhen Futian and other places stand for this type. For example, the Jilin court started with the allocation of trial resources, and set up a short and flexible case-handling team in the main departments of the trial execution. The trial team configured the members according to the model of " 1 presiding judge + Nordinary judges $+\mathrm{N}$ trial assistants". With the presiding judge as the core, the team members work together to work closely with the case handling team. The president and the director directly enrolled in the case handling team and served as the presiding judge to participate in the case. The principal focus was on the past administration to the law enforcement case. For example, according to the existing staffing, the Weihe Court adopts the $1+2+1+1$ model to integrate the original trial business units into 10 relatively fixed collegiate panels, that is, a presiding judge who is appointed by the incumbent and the president, 2 A judge, a judge assistant, and a clerk.[3]

\subsubsection{Randomly formed collegiate class}

This model is represented by the Supreme People's Court First Circuit Court, the Second Circuit Court, and some grassroots courts with a relatively small number of cases and a relatively small number of judges. For example, the First Circuit Court of the Supreme People's Court has set up a trial team for each presiding judge with one judge assistant and one clerk. When a collegiate panel needs to be formed, a computer is randomly formed to form a collegiate panel. The presiding judge.[4]

\subsection{Focus on Shanghai: trial team construction sample in Shanghai}

As a major province of receiving cases, Shanghai has followed the policy of the practice of the trial team and has formed numerous fruitful practical results. After investigation and analysis, the following outstanding experience was found:

The first is to create a quick-discovery team based on whether the case is complex or simple . For example, the Qingpu Court requires the courts to rationally allocate personnel according to the characteristics of the court, and has established a quick-discovery team with pre-litigation mediation 
and pre-litigation preparation as the main work items. The Songjiang Court divided two cases handling teams within the Criminal Court. One of the case handling teams mainly tried cases in which the guilty plea stipulations were applied, and the other case handling team tried difficult and complicated cases. The Minhang Court established a 1+3 +3brief case review team $(1$ judge +3 judge assistants +3 clerks) in the civil court. The team settled more than $50 \%$ of the courts.

The second is to set up a collegiate professional bench. According to the actual situation and professional characteristics, each institution will set up a collegiate panel with high professionalism. For instance, the Qingpu Court newly established an environmental resources trial court to intensively handle civil, commercial, and administrative cases involving environmental resources. The Songjiang Court set up a company law trial team, a financial trial team, a commercial trial team, and a foreign-related case trial team within the Civil court.

The third is to establish a specialized case-handling team with the core of the judges as the core. For example, the Pudong Court has formed 74 trial teams in 24 trials (executive) business units. Each team comprises of a number of judges, judge assistants, and clerk, one of whom is the team leader. The Songjiang court does not have a fixed presiding judge within the clerical court team. Except for the court president to participate in the trial, the court president is the presiding judge. The other cases are tried by the presiding judge.

\section{Issues that intermediate courts set up a trial team should focus on}

\subsection{The relationship between the trial team and the collegiate bench}

The trial team and the traditional collegiate bench are different in terms of personnel composition, internal work, and operational principles. The traditional collegiate panel highlights the judges, and the trial team places more emphasis on the synergy of various types of personnel.[5]The collegiate bench is a statutory trial organization composed of a number of judges or including people's jurors. The trial team also includes judicial assistants such as judge assistants and clerk. In internal work, each member of the collegial panel has the same right to evaluate the case. The members of the trial team have a different division of labor and responsibilities. For example, the judge assistant is mainly engaged in trial support affairs, and the clerk is mainly responsible for administrative affairs. In terms of operational principles, the original intention of the collegial panel is to focus on the quality of the case and guarantee the fairness and justice of the law, but the purpose of the formation of the trial team is more diversified, in addition to improving the efficiency and quality of the case, including training judges, reducing administrative management and improving judicial efficiency.

The collegiate bench is the basic trial unit of the intermediate court, so it is impossible for the construction of the trial team to be totally divorced from the original collegiate bench. Therefore, in the process of forming a trial team, it is necessary to pay attention to the construction of the unique function of the trial team, not to blindly copy the structure of the collegiate bench. Otherwise, the trial team can't realize it's worth of value.

\subsection{The relationship between the trial team and the original court}

Some scholars have said that the existing exploration of the trial team has not completely deviated from the original business court set pattern, and still retains bureaucracy, and the branding of the bureaucracy is still profound.[6]However, this paper believes that the simplification and diversion of cases is the general trend, and it is an inevitable choice to improve the efficiency of trials and the quality of trials. It is scientific and reasonable for the creative business court pattern set according to the type of case. At present, the judicial reform is drastic and has achieved many results. However, it cabled forgotten that the supporting measures related to it have not been updated in time. In practice, more than once, there has become an embarrassing situation of "The rules are not detailed enough”. Step by step is a major theme, the original rational elements should not be blindly 
abandoned, and the trial team should be constructed on the basis of the original court layout, which has great positive significance for improving the supervision and management of the trial and the uniform application of the law.

\subsection{It should reflect the characteristics of the Intermediate People's Court}

Based on the situation faced by the Intermediate Court itself, we found that the trial team of the Intermediate People's Court has two points to note: First, the Intermediate People's Court should continue to highlight the role of the collegiate bench as the basic unit of judgment. The situation is determined by Intermediate People's Court undertaking a large number of appeals and protests. The Intermediate Court should focus on the formation of the trial team in the second instance. The role of the collegiate bench as an important part of the trial team is indispensable. Therefore, it should be fully understanding the practical value of the traditional professional collegiate bench . What's more , it is of great significance to Inherit great parts.

Second, because the case type and the trial function of the Intermediate People's Court are different from the grassroots courts, the construction of the trial team needs to highlight the specialization of the trial. Cases heard by the Intermediate People's Court have the role of demonstrating and guiding the grass-roots courts. They need to create the concept of "handling cases is the guidance", and solve the problem of applying laws by hearing major, complicated, difficult, and new cases, and play a role in guiding the grass-roots courts to handle cases. This requires that the specialization of the trial should be reflected in all aspects of the construction of the trial team of the intermediate court, and plays the role of the division of labor and trial of the class as much as possible. This is also beneficial to the consensus of the members of the trial team and the application of law.[7]

\section{Exploration of building a trial team}

\subsection{Positioning the trial team}

As some scholars have said, the formation of a trial team is essentially a category of trial resources. The allocation of resources must be for the purpose of achieving or achieving a specific purpose, and therefore certain principles must be applied in this process. The establishment of the trial team of the Intermediate People's Court contains the following objectives and principles.

\subsubsection{Ease the pressure and improve the quality of case handling}

Under the dual influence of the concept of the rule of law of the masses and the reform of the registration system for the registration of the courts, the increase in the number of cases brought enormous pressure on the courts. At the same time, due to the reform of the postal system, the number of judges was limited .Judges are confronted with an increasing number of cases, which will create contradictions in human cases.

At a time when the pressure on the human case is outstanding, the trial team may be able to conduct high-quality trials of the case with the original model, thereby easing the pressure and improving the quality of the trial. As an intermediary court, even the second-instance case has the difference in simple or difficult, so the construction of the team model must take into account the resolution of the contradiction. For example, in pilot courts including the Leshan City Intermediate People's Court, the trial team's attempt to construct has a significant impact on the settlement rate.

\subsubsection{De-administration and promote flattening}

In the period before the current jurisdictional reform, the internal operating mechanism of the court is very similar to that of the general administrative organs, showing a layer-by-layer management characteristic. This kind of operation mechanism corresponds to the process of the judge's handling of the case. It is tend to have the phenomenon that the legal instrument needs the signature of the president of the court, making the opinion of president leads the judgment. This reduces the efficiency of the trial and completely violates the law of judicial operation.[8] 
"Several People's Court's Opinions on Improving the Judicial Responsibility System" introduces the concept of "flattening" into the trial team, which can effectively solve the above problems. The flattening system emphasizes streamlining the management level, which can reduce unnecessary procedures, enhance the smooth flow of the team, and convey the information up and down more quickly and not easily. At the same time, this management model also enhances the cohesiveness within the team, which is more conducive to self-management and acceptance management of the trial team. From the perspective of improving the quality of trials, the implementation of flattening management is the only way to form a trial team.

\subsubsection{Adhere to the system}

According to the current test, we found that the construction models of the various court trial teams are diverse, and this is precisely because the actual situation faced by each court is different, so the choice is different. Because different courts handle different tasks, organizations, team composition, etc., this means that the trial team is not only a version, cannot engage in "one size fits all" and "unified standard", but should allow for individualized, differentiated features.[9]

According to local conditions, practice-oriented is a point that must always be paid great attention to in the process of forming a trial team. Even though the most intermediate courts have many similarities in trial cases, we must make arrangements for judges and other support personnel in the process of constructing the trial team in light of the court's own situation, such as the region and the proportion of cases so as to maximize the satisfaction of real needs and improve the quality of trials.

\subsection{The formation mode of the trial team}

The core of the formation of the trial team is the allocation of human resources, including the division of labor of the input judges, judge assistants, clerk, and police officers. As mentioned earlier, there have been numerous different models in the practice of setting up trial teams in pilot courts. Based on its own characteristics, the grassroots courts mainly set up a trial team around a single judge or the presiding judge. The intermediate courts are more typically based on the post judges, and the assistants and clerk of the judges work closely together, work in a coordinated manner, and are relatively fixed.

In fact, the situation in different regions and different courts is different. In the process of constructing the trial team, it must be practice-oriented, so that the trial team can really play its role. Some people think that the court should set up a trial team to consider the number of cases in the court, the difficulty of the case, the ability of the judge, the jurisdictional scope, etc.Taking the Shanghai Financial Court as an example, after the relevant regulations for the construction of the Shanghai Financial Court have been issued, it is possible to initially try to construct different types of different trial teams internally, such as the securities and futures case trial team, the bankruptcy dispute trial team, and the arbitration judicial review team. Etc., specific to the staffing, it can try the $3+\mathrm{N}+\mathrm{N}$ model, that is, three judges from a collegiate bench, equipped with several judge assistants and several clerks. The presiding judge is responsible for coordinating the overall division of the case, and the issuance of the judgment documents. They are the people in charge. No matter how difficult and complicated cases are, cases should be digested within the team from beginning to the end.

\subsection{Implementation of the relevant requirements of the judicial responsibility system}

No matter which mode of trial team is chosen, it must follow the law of justice and conform to the spirit of judicial responsibility reform. The same is true of the judging team as a different thing. Separation from scientific and effective supervision will only make the system quickly degenerated or even cause harm. Take into account this, it is essential to strengthen the management and supervision of the trial team.

Due to the flattening trend of the trial team building, establishing a power lift system is an effective attempt. Making a responsible person lead the daily operation of the team and coordinate 
the division of labor. He should undertake the management of the trial work and perform the supervisory duties. For example, in the $1+\mathrm{N}+\mathrm{N}$ mode, the sole judge should Becoming the team leader, and in the $3+\mathrm{N}+\mathrm{N}$ model, a senior judge or a court leader can be the person in charge, and the responsible person must be distinguished from the collegial panel judge, not only the meaning of the procedural law. For judge assistants and clerk, it is also necessary to clarify their specific responsibilities. While being responsible for the judges, they must also have their own power boundaries.

The supporting measures related to the trial team should be updated in a timely manner. For instance, the assessment of the performance of the trial team should be accompanied by relevant measures. Some people think it is necessary to refine and distinguish the overall performance of the team and the performance of internal staff, judges and judicial assistants, so the scientific and reasonable evaluation of seeking truth from facts is the obligation of the implementation of judicial responsibility system.

\section{References}

[1] Zhou Qiang, "Report of the Supreme People's Court on the Comprehensive Deepening of Judicial Reform by the People's Court", the website link. http://www.court.gov.cn/zixunxiangqing-66802.html, visit time August 9, 2018.

[2] He Fan , "The trial team will replace the trial court?", the website link http://www.360doc.com/content/16/0910/22/33091868_589887258.shtml, visit date August 6, 2018.

[3] Sun Bing, "From "behind the scenes" to "before the stage" - the president of the Jilin Court of the Court "sit on the court" into the normal state, The "People's Court" ,vol.1,2016.

[4] ]Ma Yuanjie, "Institutional Functions and Reform Paths of Judicial Team under Judicial Responsibility System”, Law Application, vol. 11, pp. 97-102, 2016.

[5] He Fan: "The trial team will replace the trial court?", the website link http://www.360doc.com/content/16/0910/22/33091868_589887258.shtml, visit date August 6, 2018.

[6] Liu Qingwei, From "Shaping" to "Shaping the Spirit of God": Reflection and Improvement of the Establishment of New Trial Teams in Some Pilot Courts, Shandong Trial, vol. 4, pp.4247,2017 .

[7] Li Menglong, "The Relationship between Trial Team and the Collegiate Bench - From the Perspective of the Intermediate Court", "People's Justice" (Application), vol. 34, pp. 61-66, 2017.

[8] Huang Mingchun, Chen Xiguo, "Basic Positioning of the Judging Team Configuration Mode", The "People's Court Newspaper" ,vol. 8, 2017.

[9] Luo Jinyong, "How to Scientifically Build a Judging Team", "People's Court Newspaper",vol. 2,2017. 2 